\title{
A Clinical and Radiographic Assessment of Sodium Hypochlorite Versus Formocresol Pulpotomy in Primary Molar Teeth: 12-month Follow-up
}

\author{
Zahra Bahrololoomi ${ }^{1}$, Fatemeh Zarebidoki ${ }^{2}$, Atefeh Shakib ${ }^{3 *}$ \\ ${ }^{1}$ Associated Professor, Social Determinants of Oral Health Research Center, Department of Pediatric Dentistry, Shahid Sadoughi University of \\ Medical Sciences, Yazd, Iran. \\ ${ }^{2}$ Assistant Professor, Department of Pediatric Dentistry, Shahid Sadoughi University of Medical Sciences, Faculty of Dentistry, Yazd, Iran. \\ ${ }^{3}$ Pedodontist
}

\section{Abstract}

Objective: The aim of this study was to compare the clinical and radiographic success rates of pulpotomy in primary molars using formocresol versus sodium hypochlorite.

Methods: Twenty-three children aged 4-9 years with at least two primary molars requiring pulpotomy were randomly allocated into two groups. All teeth received stainless steel crown after conventional pulpotomy procedure with either $\mathrm{NaOCl}$ or formocresol. Clinical and radiographic signs/symptoms were recorded at six and 12 months. Outcomes were statistically analyzed using Fisher's exact test and Chisquare test.

Results: Clinical success rates at 6 and 12 -month follow-up in both groups was $100 \%$. At 6 -month followup, radiographic success rate for $\mathrm{NaOCl}$ and formocresol groups was $100 \%$. At 12 -month recalls, in $\mathrm{NaOCl}$ group, 20 teeth $(87 \%)$ and in formocresol group, 21 teeth $(91.3 \%)$ had radiographic success. No significant difference was found in the radiographic success rates at 12 months $(P=1.00)$. Internal root resorption was the most common radiographic pathologic finding in both groups.

Conclusion: Clinical and radiographic success rates in $\mathrm{NaOCl}$ group was comparable with formocresol group, so $\mathrm{NaOCL}$ can be suggested as an alternative for primary teeth pulpotomies. However further clinical studies with long-term follow-ups are needed.
Keywords: Formocresol; Pulpotomy; Sodium Hypochlorite; Tooth; Deciduous

Citation: Bahrololoomi Z, et al. (2021) A Clinical and Radiographic Assessment of Sodium Hypochlorite Versus Formocresol Pulpotomy in Primary Molar Teeth: 12-month Follow-up. Dentistry 3000. 1:a001 doi:10.5195/d3000.2021.124

Received: December 4, 2020

Accepted: March 6, 2021

Published: July 19, 2021

Copyright: (C2021 Bahrololoomi Z, et al. This is an open access article licensed under a Creative Commons Attribution Work 4.0 United States License.

Email:dr.1370@yahoo.com

\section{Introduction}

\section{Pulpotomy is a common}

therapeutic method for treatment

of primary teeth in which teeth

had deep carious lesions

approaching the pulp and some

cases also had a history of pain.

This pain lasted less than 20 minutes, was provoked by

chewing foods, especially sweets, did not wake the child from sleep [1].

Various medicaments are used in pulpotomy of primary teeth among which formocresol (FC) is the commonest. The reported success rate of FC pulpotomy is
$70-98 \%[2,3]$, but some studies showed the possibility of such local or systemic side effects as pulpal reactions with inflammation, necrosis, cytotoxicity, and potential mutagenic or carcinogenic effects and immunologic responses after FC use. There are also concerns 
about the effect of FC on the enamel of the succedaneums permanent teeth after pulpotomy of primary teeth [4]. Considering the side effects of FC, its substitution with a safer substance seems necessary. Therefore, in different studies, medicament and non-medicament methods have been proposed to replace FC in pulpotomy of primary teeth [5]. Sodium hypochlorite $(\mathrm{NaOCl})$ is a substance used for canal irrigation, hemostasis and removing biofilms and debris [6]. It has strong biological properties that include antimicrobial activity and organic tissue dissolution capacity [7]. It presents a wellrecognized in vitro antimicrobial activity although in some cases this solution fails to achieve a bacteria-free root canal under clinical coditions [7-9] The antimicrobial effect of $\mathrm{NaOCl}$ solutions depends on their free available chlorine, which consists of hypochlorous acid and the hypochlorite ion $[8,9]$

Clinical studies in which $\mathrm{NaOCl}$ was used for pulpotomy of primary molars, showed that its clinical and radiographic success rate was comparable with FC and ferric sulfate [4, 10]; although there are few studies on this issue. Therefore, this study was designed to assess the clinical and radiographic success rate of primary molar pulpotomy using FC and $\mathrm{NaOCl}$.

\section{Material and Methods}

This was a double-blind randomized controlled trial approved by the ethics committee of Shahid Sadoughi University of Medical Sciences (code: IR.SSU.REC.1394.107) and registered in Iranian center for registration of clinical trials (code: IRCT20150927935N5).

Totally, 25 children 4-9 years old referred to the pediatric department of dental school in Shahd Sadoughi University of Medical Sciences with at least two primary molars requiring pulpotomy entered the study. Two children (4 teeth) didn't continue the study during 12-months follow-up.

A parallel design was used, because only some of the children had at least two primary molars requiring pulpotomy. The tooth was considered the unit for randomization. On the day of the procedure before the pulpotomy was performed, the operator was given a sealed envelope that contained a letter denoting the medicament group. The patients were not informed about their group allocation. Inclusion criteria were: in clinical examination: primary molars with deep caries and pulp exposure; lack of pulp degeneration in the affected teeth (e.g. spontaneous and nocturnal pain, swelling, mobility, abscess, fistula and tenderness to percussion); in radiographic examination: lack of internal or external root resorption and furcation radiolucency; being restorable by stainless steel crowns.

Before examinations, the objectives of the study were explained for the parents and an informed consent was obtained from them.

At first, the tooth was anesthetized using lidocain $2 \%$ and epinephrine 1/80000 (Daroupaksh co., Tehran, Iran). After isolation of selected teeth with a rubber dam, caries were removed and then pulpal chamber accessed by a fissure diamond bur $\mathrm{N} \neq 330$ (Tizkavan, Tahran, Iran) in a watercooled high-speed hand-piece. For removing pulp tissue, a spoon excavator was used and after saline irrigation, cotton pellets were inserted in place for 5 minutes to induce hemostasis. If bleeding continued, the patient was excluded from the study, and if hemostasis was induced, treatment was continued in both groups. In first group, a 1:5 dilution of Buckley's FC (SSA, Produits Dentaires, Switzerland) was used for 5 minutes and in the 
second group, $\mathrm{NaOCl}$ \%\% (Sehhat, Tehran, Iran) was applied by a cotton applicator in the pulp chamber for 30 seconds. Then, in both groups, reinforced zinc oxide eugenol (Kemdent, UK) was inserted in the access cavity and in the same session, teeth were restored by stainless steel crowns (3M/ESPE, Dental Products, St. Paul, MN, USA).

All procedures were performed by postgraduate pedodontist. Clinical and radiographic outcome assessments were made by one independent experienced pedodontist who was blind to the treatment at follow-up visits. The success of treatment was determined as the absence of spontaneous pain, mobility, swelling, fistula and tenderness to percussion. Radiographic success was determined as lack of internal or external resorption, and interradicular and periapical radiolucency. All radiographs were taken by Plammeca Oy (Helsinki, Finland) using E films (Skydent, Slovakia). and the images were reevaluated by the same specialists after 7 days (intra-examiner agreement $>90 \%)$. Data were analyzed by SPSS (Ver. 20) using Fisher's exact test and ci square test. The $p$ value $<0.05$ was considered significant.

\section{Results}

This study was started with 25 children 4-9 years old (13 females and 12 males) with mean age of 6.5 years. Fifty primary molars were randomly allocated into two treatment groups. Two children (4 teeth) didn't continue the study during 12-months follow-up. Therefore, 23 patients were evaluated.

Table 1 shows the distribution of the teeth in two groups. There was not a statistically significant difference between two groups regarding gender, age, tooth type and tooth location ( $P>0.05$ )

Clinical findings:

From 46 pulpotomized teeth at 6 and 12 -month recalls, $100 \%$ of the cases in both $\mathrm{FC}$ and $\mathrm{NaOCl}$ groups showed clinical success.

Radiographic findings:

At 6-month recall, $100 \%$ of cases in both groups showed radiographic success (Fig. 1). After 12 months, in $\mathrm{NaOCl}$ group, three teeth (13\%) showed internal resorption, among which two teeth showed external resorption and involvement of inter-radicular bone as well; and in FC group, failure was observed in two teeth (8.7\%), among which one tooth showed internal resorption (Fig 2) and another tooth showed both internal resorption and involvement of inter-radicular bone. The most frequent radiographic failure was internal resorption without insignificant difference between groups $(P>0.05)$.

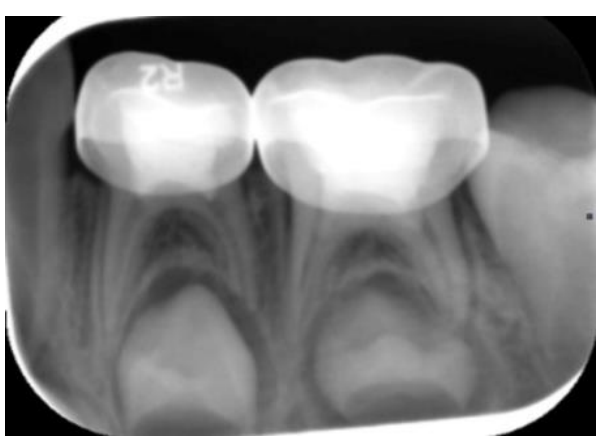

Figure 1. successful treatment of $\mathrm{NaOCL}$ pulpotomy of lower left second primary molar after 12 months follow-up.

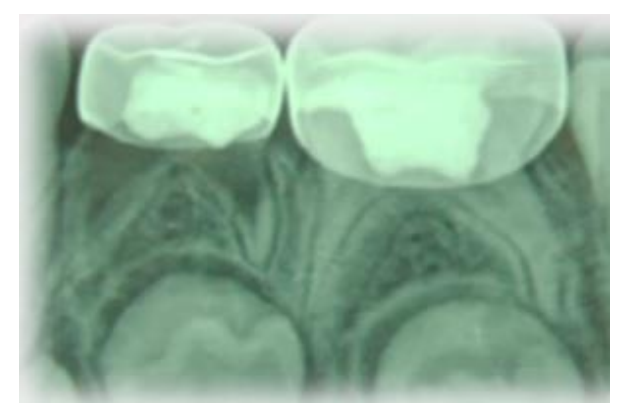

Figure 2. Radiographic failure of FC pulpotomy on lower left first primary molar with internal root resorption after 12 months follow-up.

The 12-month radiographic success rate was $87 \%$ and $91.3 \%$ in $\mathrm{NaOCl}$ and FC groups, respectively, and the difference was not statistically significant $(P=1.00)$ (table 2).

Table 1. Distribution of pulpotomied primary molars according to the type of teeth. 


\begin{tabular}{|c|c|c|c|c|c|c|c|c|c|c|c|c|}
\hline \multirow{3}{*}{$\begin{array}{l}\text { Treatment } \\
\text { group }\end{array}$} & \multicolumn{12}{|c|}{ Number of teeth } \\
\hline & \multicolumn{3}{|c|}{ First primary molar at 6 months } & \multicolumn{3}{|c|}{$\begin{array}{l}\text { Second primary molar at } 6 \\
\text { months }\end{array}$} & \multicolumn{3}{|c|}{$\begin{array}{l}\text { First primary molar at } 12 \\
\text { months }\end{array}$} & \multicolumn{3}{|c|}{$\begin{array}{l}\text { Second primary molar at } 12 \\
\text { months }\end{array}$} \\
\hline & Maxillary & Mandibular & Total & Maxillary & Mandibular & Total & Maxillary & Mandibular & Total & Maxillary & Mandibular & Total \\
\hline FC & 9 & 5 & 14 & 4 & 7 & 11 & 8 & 5 & 13 & 3 & 7 & 10 \\
\hline $\mathrm{NaOCl}$ & 6 & 10 & 16 & 9 & 0 & 9 & 5 & 10 & 15 & 8 & 0 & 8 \\
\hline
\end{tabular}

Table 2. Comparison of the clinical and radiographic success rate in primary molars pulpotomied by $\mathrm{FC}$ and $\mathrm{NaOCl}$ at 6 and 12 -month follow-ups.

\begin{tabular}{|c|c|c|c|c|c|c|c|c|}
\hline & Success & (percent & & & & & & \\
\hline \multirow[t]{3}{*}{ Treatment group } & \multicolumn{4}{|l|}{ Clinical } & \multicolumn{4}{|c|}{ Radiographic } \\
\hline & \multicolumn{2}{|l|}{6 month } & \multicolumn{2}{|l|}{12 month } & \multicolumn{2}{|l|}{6 month } & \multicolumn{2}{|l|}{12 month } \\
\hline & Success & Failure & Success & Failure & Success & Failure & Success & Failure \\
\hline $\mathrm{FC}$ & $23(100)$ & 0 & $23(100)$ & 0 & $23(100)$ & 0 & 21 (91.3) & $2(8.7)$ \\
\hline $\mathrm{NaOCl}$ & $23(100)$ & 0 & $23(100)$ & 0 & $23(100)$ & 0 & $20(87)$ & $3(13)$ \\
\hline
\end{tabular}

\section{Discussion}

The first objective of pulp therapy is maintaining the integrity and health of oral tissue. It is necessary to try to maintain pulp vitality [11]. Pulp therapy has been successfully performed for severely destructed primary molars by Buckley's FC since 1904. Controversy to use this substance was due to its potential mutagenic and carcinogenic effect; so other drugs have been introduced with different success rates and costs [12].
Previous studies used $\mathrm{NaOCl} 2.5$ to 5.25 percent. In the current study, similar to Al-Mutairi et al.[13], Vargas et al.[4], Vostak et al.[10], and Tzu-Ying Li studies[14], $\mathrm{NaOCl}$ $5 \%$ was used. Only in the studies conducted by Ruby et al.[12] and Shabzendehdar et al.[15] NaOCl $3 \%$ was used. Akay et al.[16] Who assessed the effect of $\mathrm{NaOCl}$ on disinfection before application of the substance covering pulp, used $\mathrm{NaOCl} 5 \%$ [16]. According to the studies and considering the difficulties in preparing $\mathrm{NaOCl} 3 \%$, concentration of $5 \%$ was used in the present study.

In the current study, clinical success rate of $\mathrm{NaOCl}$ and $\mathrm{FC}$ at 6 and 12 -month recalls was $100 \%$. Radiographic success rate at 6 month recall was $100 \%$ in both groups which was consistent with the results of Farsi et al. [17], although other studies reported success rate to be between 86 $99 \%[4,10,12-15,18]$.

Radiographic success rate at 12 month recall was $91.3 \%$ and $87 \%$ in $\mathrm{FC}$ and $\mathrm{NaOCl}$ groups, 
respectively, which was in agreement with some other studies $[12,13,15]$.

Al_Mutairi et al. found 12-month clinical and radiographic success rate of $\mathrm{NaOCl}$ to be 94.6 and $86.5 \%$, respectively [13]. They used a method similar to our study. In the study conducted by Ruby et al. the success rate of $\mathrm{NaOCl}$ was $100 \%$, though with a lower radiographic success rate, i.e. $90 \%$. They didn't find a significant difference between the success rate of $\mathrm{NaOCl}$ and $\mathrm{FC}$ which was consistent with the results of the current study; although they used $\mathrm{NaOCI} 3 \%$ [12]. In the study of Shabzendehdar et al. in agreement with the current study, there was not a significant difference between two substances. They used $\mathrm{NaOCl} 3 \%$, but duration of substance application was $30 \mathrm{~s}$, similar to the current study. Another difference between the studies was that they performed pulpotomy only on mandibular first molars and their participants had at least one tooth requiring pulpotomy [15]. Tzu-Ying Li et al. conducted a retrospective study with a larger sample size and a longer duration of recall ( 24 months).

The most frequent radiographic finding in the present study was internal resorption which was observed in $21.7 \%$ of teeth at 12 month recall. Although no clinical signs were seen in these teeth which was consistent with the results of the previous studies [4, $10,14,15,18]$.

We couldn't find a satisfactory explanation for the internal resorption occuring after pulpotomy; even though during pulpotomy it is possible that abnormal pulpal tissue remains in the place, and if the inflammation extends to the entrance of the pulp canal, odontoclasts will be attracted to the area [19].

Internal resorption may occur due to zinc oxide eugenol use, because eugenol is irritant for pulp and may induce pulp inflammation. The fixing effect of FC can probably prevent the irritating effect of eugenol, and the hemostatic properties of $\mathrm{NaOCl}$ may prevent the necrosis layer to be formed [20].

Bony changes may lead to the formation of abscess, fistula, pain and mobility of the tooth, while internal resorption is limited to the tooth and is from dental origin which was explained earlier. Internal resorption is not so important clinically, and it is possible that the problem occurs after pulpotomy without any alarming signs for the patient and the dentists, and it may be accidentally discovered in radiography[21].

Other radiographic failures include external resorption and bone lucency which are among bony changes which are more important than internal resorption in their effect on the development of permanent teeth. These changes were fortunately less frequent than internal resorption in the current study.

The failures after treatment of vital pulp and eventual failure in the formation of a calcified bridge on the vital pulp depends on the patient's age, the degree of surgical trauma, pressure during sealing, selection of inappropriate covering substance, low patient's resistance threshold and the presence of microorganisms and the eventual infection.

In summary, the reason for difference between studies is probably due to different methods, age range of the participants, difference in tooth type, design of the study and sample size.

It is recommended that clinical studies with larger sample size and longer duration of recalls be performed.

\section{Conclusion}


The findings of the current study showed that clinical and radiographic success rate of $\mathrm{NaOCl}$ is comparable to FC. A substance covering the pulp should have bacteriocidal and biocompatibility properties with low cost. $\mathrm{NaOCl}$ has all these properties and is inexpensive and easily available.

\section{Conflicts of interest}

The authors deny conflicts of interest to this study.

\section{Acknowledgment:}

The authors wish to thank the vice chancellor of research of Shahid Sadoughi university of Medical sciences.

\section{References}

1. Farooq NS, Coll J, Kuwabara A, Shelton P. Success rates of formocresol pulpotomy and indirect pulp therapy in the treatment of deep dentinal caries in primary teeth. Pediatric Dentistry. 2000;22(4):278-86.

2. Haghgoo R, Abbasi F. A histopathological comparison of pulpotomy with sodium hypochlorite and formocresol. Iran Endod J. 2012;7(2):60-2.

3. Bahrololoomi Z, Fekrazad R, Zamaninejad S. Antibacterial effect of diode laser in pulpectomy of primary teeth. Journal of lasers in medical sciences. 2017;8(4):197.
4. Vargas KG, Packham B, Lowman D. Preliminary evaluation of sodium hypochlorite for pulpotomies in primary molars. Pediatr Dent. 2006;28(6):511-7.

5. Bahrololoomi

Moeintaghavi A, Emtiazi $M$, Hosseini G. Clinical and radiographic comparison of primary molars after formocresol and electrosurgical pulpotomy: a randomized clinical trial. Indian J Dent Res. 2008;19(3):219-23.

6. Poggio $C$, Arciola CR, Dagna A, Chiesa M, Sforza D, Visai L. Antimicrobial activity of sodium hypochlorite-based irrigating solutions. Int J Artif Organs. 2010;33(9):654-9.

7. Tejada $S$, Baca $P$, FerrerLuque CM, Ruiz-Linares $M$, Valderrama MJ, Arias-Moliz MT. Influence of dentine debris and organic tissue on the properties of sodium hypochlorite solutions. Int Endod J. 2018.

8. Arias-Moliz MT, Morago A, Ordinola-Zapata $R$, Ferrer-Luque $C M$, Ruiz-Linares $M$, Baca $P$. Effects of Dentin Debris on the Antimicrobial Properties of Sodium Hypochlorite and Etidronic Acid. J Endod. 2016;42(5):771-5.

9. Bystrom A, Sundqvist G. The antibacterial action of sodium hypochlorite and EDTA in 60 cases of endodontic therapy. Int Endod J. 1985;18(1):35-40.
10. Vostatek SF, Kanellis MJ, Weber-Gasparoni K, Gregorsok RL. Sodium hypochlorite pulpotomies in primary teeth: a retrospective assessment. Pediatr Dent. 2011;33(4):327-32.

11. Shayegan A, Atash R, Petein M, Abbeele AV. Nanohydroxyapatite used as a pulpotomy and direct pulp capping agent in primary pig teeth. J Dent Child (Chic). 2010;77(2):77-83.

12. Ruby JD, Cox CF, Mitchell SC, Makhija S, Chompu-Inwai P, Jackson J. A randomized study of sodium hypochlorite versus formocresol pulpotomy in primary molar teeth. Int J Paediatr Dent. 2013;23(2):14552.

13. Al-Mutairi MA, Bawazir OA. Sodium hypochlorite versus Formocresol in primary molars pulpotomies :a randomized clinical trial. Eur J Paediatr Dent. 2013;14(1):33-6.

14. Li T-Y, Chuang L-C, Tsai Al. $A$ retrospective study of sodium hypochlorite pulpotomies in primary molars. Journal of Dental Sciences. 2016;11(3):261-5.

15. Shabzendedar M, Mazhari $F$,Alami M, Talebi M. Sodium hypochlorite vs formocresol as pulpotomy medicaments in primary molars: 1-year follow-up. Pediatr Dent. 2013;35(4):329-32. 
16. Akcay M, Sari S, Duruturk L, Gunhan O. Effects of sodium hypoclorite as disinfectant material previous to pulpotomies in primary teeth. Clin Oral Investig. 2015;19(4):803-11.

17. Farsi DJ, El-Khodary HM, Farsi NM, El Ashiry EA, Yagmoor MA, Alzain SM. Sodium Hypochlorite Versus Formocresol and Ferric Sulfate Pulpotomies in Primary Molars: 18-month Follow-up. Pediatr Dent. 2015;37(7):535-40.

18. Ghasemi D, Dehghan Z. One Year Comparison of Clinical and Radiographic Success Rate of Ferric Sulfate and Sodium Hypochlorite for Primary Molar Teeth Pulpotomy. Journal of Mashhad Dental School. 2014;38(1):37-44.

19. Chin JR, Kowolik JE, Stookey GK. Dental caries in the child and adolescent. McDonald and Avery's Dentistry for the Child and Adolescent (Tenth Edition): Elsevier; 2016. p. 155-76.

20. Smith NL, Seale NS, Nunn ME. Ferric sulfate pulpotomy in primary molars: a retrospective study. Pediatr Dent. 2000;22(3):192-9.

21. Fuks AB, Bimstein E. Clinical evaluation of diluted formocresol pulpotomies in primary teeth of school children. Pediatr Dent. 1981;3(4):321-4. 